\title{
CORRESPONDENCE
}

\section{Is the unadjusted ICU mortality a good indicator of quality of ICU care?}

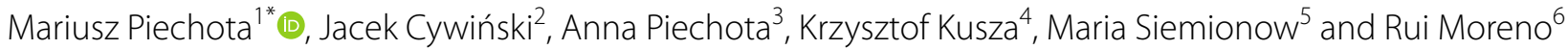

(c) 2017 Springer-Verlag GmbH Germany and ESICM

Dear Editor,

We read with great interest the letter by Weigl et al. comparing ICU mortality in selected European countries. The authors reported a significantly higher mortality in Poland (42\%) as compared to other countries (6.7-17.8\%) [1]. They concluded that the results "could be useful for stimulating improvement of critical care services in Poland" [1].

While Weigl et al. should be commended for their effort to inform the readers about variability in ICU mortality across Europe, we are very concerned about the fact that they reported and interpreted unadjusted mortality rates.

We do not question the presented ICU mortality rates in Poland and we concur with the authors' statement that the rates are high; however, we want to point out why such a simplistic interpretation is unsatisfactory and scientifically incorrect.

The problem with the report, in our opinion, is the fact that authors failed to present the severity of the patients' condition at the time of ICU admission in each country. It is well documented that objectively assessed patient condition (for instance with the APACHE II scale) correlates with ICU mortality. Rowan et al. [2] demonstrated that mortality in patients with APACHE II score 15-19, $20-24$, and $25-29$ was $18.8 \%$ (17.1-20.5), $37.9 \%$ (35.543.3 ), and $56.9 \%$ (53.6-60.2), respectively.

Data form the Polish National Consultant shows that average APACHE II score at the time of ICU admission was 26 in 2015 (Table 1). It was significantly higher than

\footnotetext{
*Correspondence: mariuszpiechota@poczta.onet.pl

${ }^{1}$ Department of Anaesthesiology and Intensive Therapy-Centre for Artificial Extracorporeal Kidney and Liver Support, The Dr Wł. Biegański Regional Specialist Hospital, Kniaziewicza 1/5, 91-347 Łódź, Poland Full author information is available at the end of the article
}

in the Netherlands and Sweden, whose average ICU admission APACHE II scores were reported to be around 15 and not surprisingly these countries had lower ICU mortality (Table 1).

Another important consideration completely ignored by Weigl et al. is the difference in the number of ICU beds available in each of the compared countries; for instance in Great Britain and Germany there were 3.3 and 24 ICU beds per 100,000 people, respectively (cf. 7.12 in Poland). It was shown that number of available ICU beds per capita correlates with mortality [5].

In our opinion, unadjusted mortality rates are impossible to meaningfully interpret and certainly can lead to erroneous conclusions, in particular when the patient severity mix is not taken into consideration [6]. It seems that use of standardized mortality ratio (SMR), which was approved by ESICM as one of nine quality and safety indicators in ICU care, would be a more meaningful way to compare mortality in different European countries [6].

Published SMR data from Poland and from any other European countries for that matter, except for Denmark, is scant. However, the SAPS III SMR available from a single center in Poland was 0.98 (0.74-1.28) and comparable to that in other European countries with lower unadjusted mortality (Table 1).

Although we are not disputing the unadjusted mortality rates presented by Weigl et al., we respectfully disagree with their interpretation, suggesting that unadjusted mortality directly represents the quality of ICU care.

We hope that in the future SMR will be widely reported in each country to allow more objective comparison of the quality of care delivered in different intensive care units across Europe. 


\section{Table 1 Intensive care units in selected European countries: basic statistics}

\begin{tabular}{|c|c|c|c|c|c|}
\hline Country & $\begin{array}{l}\text { Ratio of intensive therapy } \\
\text { beds for adults per } 100,000 \\
\text { population }\end{array}$ & $\begin{array}{l}\text { APACHE II score, mean } \pm \text { SD } \\
\text { (median, IQR) }\end{array}$ & ICU mortality (\%) & Hospital mortality (\%) & SMR, mean $(95 \% \mathrm{CI})$ \\
\hline Netherlands & $8.4[5]$ & $15^{\mathrm{a}}$ & $8.9[1]$ & $13.0[1]-15.7^{\mathrm{a}}$ & $\begin{array}{l}0.95(0.93-0.98) \\
\text { APACHE II SMR }\end{array}$ \\
\hline Sweden & $5.8^{a}-8.7[3]$ & $(15,9-22)^{a}$ & $6.7[1]-7.2^{a}$ & $13.5^{\mathrm{a}}-15.0[1]$ & NA \\
\hline UK & $3.5^{\mathrm{a}}-7.42[3]$ & $20.5 \pm 8.53^{a}$ & $29.2[4]$ & $38[4]$ & $\begin{array}{l}1.23(1.12-1.25) \\
\text { APACHE III SMR }\end{array}$ \\
\hline Poland & $7.12^{\mathrm{a}}$ & $26.0^{c}-27.1 \pm 10.4^{b}$ & $\begin{array}{l}39.7^{c}-41.5^{b} \\
-42.0[1]\end{array}$ & $44.7^{b}-47.1[1]$ & $\begin{array}{l}0.98(0.74-1.28) \\
\text { SAPS III SMR }\end{array}$ \\
\hline
\end{tabular}

Cl confidence interval, ICU intensive care unit, IQR interquartile range, NA not available, SAPS simplified acute physiology score, SD standard deviation, SMR standardized mortality ratio, $A P A C H E$ acute physiology and chronic health evaluation

a Data obtained after searching the Pubmed database

b Based on the data contained in the articles cited by Weigl et al. in the ESM

c According to data for the first half of 2015 supplied by the Polish National Consultant

\section{Author details}

${ }^{1}$ Department of Anaesthesiology and Intensive Therapy-Centre for Artificial Extracorporeal Kidney and Liver Support, The Dr Wł. Biegański Regional Specialist Hospital, Kniaziewicza 1/5, 91-347 Łódź, Poland. ${ }^{2}$ Departments of Outcomes Research and General Anesthesiology, Anesthesiology Institute, Cleveland, OH, USA. ${ }^{3}$ Department of Insurance, Faculty of Economics and Sociology, University of Łódź, Łódź, Poland. ${ }^{4}$ Chair and Department of Anaesthesiology and Intensive Care, Poznań University of Medical Sciences, Poznań, Poland. ${ }^{5}$ Department of Orthopaedics, University of Illinois at Chicago, Chicago, IL, USA. ${ }^{6}$ Hospital de São José, Centro Hospitalar de Lisboa Central, Lisbon, Portugal.

\section{Compliance with ethical standards}

\section{Conflicts of interest}

The authors declare that they have no conflict of interest.

Accepted: 4 August 2017

Published online: 25 August 2017

\section{References}

1. Weigl W, Adamski J, Gorynski P, Kanski A, Hultstrom M (2017) Mortality rate is higher in Polish intensive care units than in other European countries. Intensive Care Med. doi:10.1007/s00134-017-4804-2

2. Rowan KM, Kerr JH, Major E, McPherson K, Short A, Vessey MP (1993) Intensive Care Society's APACHE II study in Britain and Ireland - I: variations in case mix of adult admissions. BMJ 307:972-977

3. Prin M, Wunsch H (2012) International comparisons of intensive care: informing outcomes and improving standards. Curr Opin Crit Care 18:700-706. doi:10.1097/MCC.0b013e32835914d5

4. Wunsch H, Angus DC, Harrison DA, Linde-Zwirble WT, Rowan KM (2011) Comparison of medical admissions to intensive care units in the United States and United Kingdom. Am J Respir Crit Care Med 183:1666-1673. doi:10.1164/rccm.201012-19610C

5. Wunsch $H$, Angus DC, Harrison DA et al (2008) Variation in critical care services across North America and Western Europe. Crit Care Med 36:2787-2793. doi:10.1097/CCM.0b013e318186aec8

6. Rhodes A, Moreno RP, Azoulay E et al (2012) Prospectively defined indicators to improve the safety and quality of care for critically ill patients: a report from the Task Force on Safety and Quality of the European Society of Intensive Care Medicine (ESICM). Intensive Care Med 38:598-605. doi:10.1007/s00134-011-2462-3 